University of Konstanz

Department of Economics

\title{
Recovering Delisting Returns of Hedge Funds
}

\author{
James E. Hodder, Jens Carsten Jackwerth, \\ and Olga Kolokolova
}

Working Paper Series

2012-34

http://www.wiwi.uni-konstanz.de/forschung/ 


\title{
Recovering Delisting Returns of Hedge Funds
}

\author{
James E. Hodder \\ Jens Carsten Jackwerth \\ Olga Kolokolova
}

First draft: March 11, 2008

This version: September 24, 2012

\begin{abstract}
Numerous hedge funds stop reporting each year to commercial data bases, wreaking havoc with analyzing investment strategies which incur the unobserved delisting return. We use estimated portfolio holdings for funds-of-funds to back out estimated hedge-fund delisting returns. For all exiting funds, the estimated mean delisting return is insignificantly different from the average monthly return for live hedge funds. However, funds with poor prior performance and no clearly stated delisting reason had a significantly negative estimated mean delisting return of $-5.97 \%$, suggesting that a shock to their returns "tips them over the edge" and leads to delisting.
\end{abstract}

James E. Hodder, University of Wisconsin-Madison, (608) 262-8774, jhodder@bus.wisc.edu

Jens Jackwerth, University of Konstanz, +49-7531-882038

jens.jackwerth@uni-konstanz.de

Olga Kolokolova, Manchester Business School, +44-(0)161 3062081

olga.kolokolova@mbs.ac.uk

We would like to thank the following for helpful comments on earlier versions of the paper: Kostas Iordanidis, Veronika Krepely Pool, Ingmar Nolte, Winfried Pohlmeier, and seminar participants at the University of Cyprus-Nikosia, Humboldt University, IESE, the University of Konstanz, Universitat Pompeu Fabra, and the University of Zurich. 


\section{Recovering Delisting Returns of Hedge Funds}

Each year, a substantial percentage of hedge funds stop reporting their results to publicly available databases. For example, the annual average "delisting" rate was $14.55 \%$ in the data used for this paper. ${ }^{1}$ That data is a combined database created from six major commercial databases (ALTVEST, BarclayHedge, CISDM, Eurekahedge, HFR, and TASS) for January 1994 - June 2009.2 Typically, delisting funds are described as "dead funds"; but it is clear that not all of them have ceased to exist. The information in the databases is self-reported by the funds, with only $23.59 \%$ of dead funds indicating they were being liquidated. Indeed, another $2.08 \%$ indicate that they stopped providing their returns because they closed to further investments (potentially due to stellar performance and large previous inflows of investment capital); and some $\quad 0.97 \%$ state that they were merged with another hedge fund. Moreover, the remaining $73.36 \%$ of delisted funds either did not indicate why they ceased reporting or provided noninformative statements such as "requested by manager".

If one is studying hedge-fund performance, delisting raises the issue of what return should be attributed to delisting funds for the period when they stop reporting. One possibility for addressing the missing delisting returns is to simply drop the last period from the analysis, but that ignores the fact that fund investors will actually experience the delisting return. In contrast, Posthuma and van der Sluis (2004) used $0 \%,-50 \%$, and $-100 \%$ to cover a wide range of possibilities for the unknown delisting return. This drew a strong response from two practitioners, Van and Song $(2005$, p.7), who call the assumption of a $-50 \%$ delisting return

\footnotetext{
${ }^{1}$ In what follows, we will use the terms "delist" and "exit" to equivalently indicate that the fund has stopped reporting its performance to database providers.

${ }^{2}$ Our versions of the respective databases cover somewhat differing time periods; but in the aggregate, the combined data spans the January 1994 - June 2009 period. There is also overlapping coverage of some funds, and we adjust for that overlap.
} 
"outrageous". However, if a fund has suffered massive losses and is being liquidated, a large negative delisting return is definitely possible. This would be particularly likely if the fund had large illiquid positions that would be difficult to value and sell. Such a fund's mark-to-market valuation prior to delisting could seriously underestimate the extent of losses that would be incurred with liquidation, presumably under adverse circumstances. Moreover, for the vast majority of funds, we do not know why they stopped reporting.

In this paper, we develop a methodology for estimating delisting returns based on a fundof-funds (FoF) being a portfolio of positions in individual hedge funds, some of which may stop reporting in any given period. ${ }^{3}$ If we had direct information on the actual FoF portfolio positions, it would be straightforward to back out returns for delisting funds using that information plus the FoF returns and the returns of live hedge funds for the delisting month. Unfortunately, we do not have that information on FoF portfolio positions. Instead, we estimate those portfolio holdings through a matching algorithm related to principal component analysis. Once we have inferred the portfolio holdings (positions in hedge funds) for each FoF in our sample, we can obtain delisting returns during the next period based on the difference between the observed next-period return for each FoF and that period's return from its estimated portfolio holdings in live (still reporting) hedge funds. An issue with our matching algorithm is the potential for mismatches where the estimated FoF portfolio contains a different number of delisted funds than truly occurred for that FoF during the period. We develop an adjustment to correct for this bias and report below estimates using that methodology.

\footnotetext{
3 Fung and Hsieh (2000) as well as Fung, Hsieh, Naik, and Ramadorai (2008) have also noted that FoF returns implicitly incorporate the delisting returns of individual hedge funds; however, they do not use the portfolio connection to actually back out the delisting returns. Nevertheless, Fung, Hsieh, Naik, and Ramadorai (2008, page 1778) do point out that the absence of delisting returns leads to a situation where a "fund-of-fund's return more accurately reflects the losses experienced by investors in the underlying hedge fund (albeit indirectly)."
} 
We find that the estimated mean delisting return for all exiting funds is negative but not significantly different from the mean monthly return of $0.56 \%$ for all hedge funds in our sample during January 2000 - June 2009. Thus, we find that the estimated average delisting return is nowhere near large negative values of $-50 \%$ or $-100 \%$. We document some persistence in the delisting returns. The sub-group of hedge funds that delist after having positive average returns over the previous six months tends to have higher delisting returns than the average hedge fund. Symmetrically, hedge funds that delist after having negative average returns tend to have negative delisting returns. The difference between the mean delisting returns for these two groups is significant $(\mathrm{p}=0.052)$, and the group with poor average performance over the previous six months also has a mean delisting return that is significantly below the average hedge fund return of $0.56 \%$ per month.

Further examining these two groups, we find that the negative mean delisting return for funds with poor average performance over the previous six months is largely due to funds that did not state a clear reason for delisting. Those funds had an estimated mean delisting return of $-5.97 \%$. On the other hand, funds that stated they were being liquidated after a negative average return over the previous six months had an estimated mean delisting return of $-0.59 \%$ which is not significantly different from the average monthly return for live hedge funds. An explanation consistent with these patterns centers on the surprise element of negative shocks. A negative shock after a period of poor performance might lead to a sudden delisting without stating a reason. On the other hand, managers that plan to liquidate a fund due to a history of poor performance seem likely to follow through on that decision independent of the delisting return.

We also find a seemingly curious result for funds which delist after having a positive mean return over the prior six months and state that they are being liquidated. These funds not only had positive average returns over the previous six months but also have a rather high 
average delisting return of $5.46 \%$ per month. However, that return estimate is not significantly different from the average monthly hedge fund return of $0.56 \%$ due to a relatively small sample and noisy delisting return estimates. Moreover, these funds are small and many experienced relatively weak fund flow over the 3 years prior to delisting. It seems likely that they did not attract enough capital to become sufficiently profitable for their managers, who eventually decided to liquidate despite positive returns.

There is a literature which explores hedge-fund performance prior to delisting. ${ }^{4}$ However, there have been few attempts to examine performance after delisting. Ackermann, McEnally, and Ravenscraft (1999) used a combined data set with underlying data from two providers, Managed Account Reports, Inc. (MAR) and Hedge Fund Research, Inc. (HFR). During 1993-1995, their combined data included 37 "terminated" funds (liquidated, restructured, or merged into another fund) plus an additional 104 funds that stopped reporting without a clear indication as to why they ceased reporting. That is, a total of 141 delisting funds. Those authors were able to obtain information on returns for some fraction of the terminated funds (only) via a request to HFR regarding funds that had been listed in the HFR portion of the joint database. Thus, the information refers to only some portion of the 37 terminated funds rather than all 141 delisting funds. The response from HFR indicated an average return for the terminating funds after delisting of $-0.7 \%$, with a surprisingly rapid final redemption that occurred on average only 18 days after delisting. It would appear that some of the terminating funds were in the process of liquidating while still reporting returns. Unfortunately, that data is rather early (1993-1995), predating the boom in the hedge-fund industry; and it is based on a relatively small sample (at most 37 terminating funds).

\footnotetext{
${ }^{4}$ See for example, Brown, Goetzmann, and Ibbotson (1999), ter Horst and Verbeek (2007), as well as Liang (2000).
} 
Agarwal, Fos, and Jiang (2010) also perform some analysis of delisting returns, although the authors largely focus on an attempt to estimate "self-reporting bias" using information from 13F filings with the SEC which primarily address US equity and some option positions. The analysis covers a longer period from 1980 to 2007; however, their reported number of delisting hedge funds is still rather limited -- only 187 instances. Their estimated mean delisting return of $-0.72 \%$ is quite similar to that reported by Ackermann, McEnally, and Ravenscraft (1999). ${ }^{5}$ However, the $13 \mathrm{~F}$ filings are quarterly and involve sizable management firms (AUM over $\$ 100$ million) rather than individual hedge funds. This suggests their estimated returns are for management firms and may involve multiple funds.

There is also a recent paper by Aiken, Clifford, and Ellis (2010) that estimates hedge fund returns based on reported quarterly hedge fund holdings during 2004-2009 by each of 80 FoFs that were registered with the SEC. That paper also focuses on self-reporting bias but does report some results for delisting hedge funds. Those results indicate delisting funds underperform funds that remain listed by approximately $0.45 \%$ monthly during the quarter after delisting. That estimate is on a risk-adjusted basis using the Fung and Hsieh 7-factor model. However, the delisting funds in this paper (as in Agarwal, Fos, and Jiang (2010)) are not liquidated or merged but continuing to operate. Moreover, a potentially important issue with this paper is that it only checks for listing (delisting) in two databases (TASS, and BarclayHedge). Hence, some of their delisting funds may still be listed in one or more of the other commercial databases. Also, delisting events in the other databases are being ignored by Agarwal, Fos, and Jiang (2010).

The next section provides details on the matching algorithm and the econometric model of FoF returns. In Section II, we describe our empirical design and basic characteristics of the data

\footnotetext{
5 The delisting funds in Agarwal, Fos, and Jiang (2010) are not liquidated or merged but continuing to operate in contrast to the funds used in the $-0.7 \%$ estimate of Ackermann, McEnally, and Ravenscraft (1999).
} 
sample. Results are contained in Section III with several robustness checks described in Section IV. Section V concludes.

\section{The Basic Model}

Since we do not have precise information on portfolio holdings for each FoF in our sample, we need a procedure for estimating those holdings. We use a matching algorithm described below that is conceptually related to principle components. As a preliminary step, we need to "gross up" the reported FoF returns to a pre-fee level - that is, to the return level before management and incentive fees were extracted by the FoF. That pre-fee FoF return is the return on a portfolio of post-fee hedge fund returns (management and incentive fees having already been extracted by the respective hedge funds). As our FoF and hedge-fund return data is all post-fee, we transform the FoF returns to a pre-fee basis using an algorithm closely related to Brooks, Clare, and Motson (2007) and detailed in Kolokolova (2011).

In our implementation, we use a 36-month rolling window and consider only FoFs and hedge funds which report returns for all months in the relevant window. As with many other implementation choices for our basic methodology, we have examined robustness to variations in the choice of a 36-month window. To avoid cluttering the exposition, we defer discussion of such robustness checks until Section IV below. As a general statement, our qualitative results are robust; but there can be some variation in point estimates.

For each FoF, we find the hedge fund whose (post-fee) returns are most highly correlated with the (pre-fee) returns of that FoF. Then, we regress the FoF returns on the chosen hedge fund and obtain the residual returns. In these regressions, we impose upper and lower limits on the estimated weights (more details below) to assure a reasonable level of portfolio diversification and avoid highly concentrated holdings that would be rather unlikely in FoF portfolios. Next, we 
find a second hedge fund that is now the most highly correlated with the residual returns for that FoF. We add that hedge fund to the portfolio, find new residual returns, and proceed in this fashion until we have 15 hedge funds in the portfolio. ${ }^{6}$ Additionally, after having added the 10th hedge fund, we require the estimated portfolio weights in all subsequent portfolios to sum up to unity.

Once we work out the set of matched hedge funds for each FoF, we are ready to model the pre-fee returns of the FoF as a portfolio of the (post-fee) returns on the matched hedge funds. Hedge funds within each match are indexed by $j$. The (pre-fee) FoF returns are always indicated with an upper-case $R$, and the live hedge fund returns (post-fee) are denoted with a lower-case $r_{L}$. We use $\mathrm{T}=36$ consecutive returns to estimate the following regression model for each FoF, with those FoFs indexed by $i$ and time periods (months) by $t$ :

$$
\begin{aligned}
& \mathrm{R}_{\mathrm{it}}=\left[\mathrm{r}_{\mathrm{Lt}}\right] \beta_{\mathrm{i}}+\varepsilon_{\mathrm{it}}, \mathrm{t}=1, \ldots, \mathrm{T} \text {, and } \mathrm{i}=1, \ldots, \mathrm{N}_{\mathrm{FoF}} \\
& \text { s.t. } \beta_{\min } \leq \beta_{\mathrm{i}} \leq 0.10, \sum_{\mathrm{j}} \beta_{\mathrm{ij}}=1
\end{aligned}
$$

where $N_{F o F}$ is the number of all possible subsamples of $\mathrm{T}$ consecutive returns for the FoFs reporting to our database. We do not make any assumptions concerning the distribution of the error term $\varepsilon_{i t}$ except that it has a zero mean.

Since equation (1) implicitly has unlevered returns for the FoFs, our main results utilize only those FoFs that report not using leverage. ${ }^{7}$ These FoFs attempt to remain close to fully invested, and we do not include the riskless asset as one of the potential investments. In order to

\footnotetext{
${ }^{6}$ In the robustness section, we allow up to 26 hedge funds in each portfolio, which matches the reported average for FoFs in our data.

7 We reexamine this restriction as well as others mentioned below in the robustness section.
} 
insure economically sensible portfolio positions, we restrict the loadings $\beta_{i}$ (portfolio weights for $\mathrm{FoF}_{\mathrm{i}}$ ) on the matched hedge funds to be smaller than 0.10 and larger than some minimal value $\beta_{\min }$. For the main part of our analysis, $\beta_{\min }$ is set at 0.02 . We further assume that each FoF is fully invested in its set of matched hedge funds..$^{8}$

We now turn to the fitted return of the FoF in period $\mathrm{T}+1$. If all the hedge funds in that particular FoF portfolio are still alive, then the fitted return is simply calculated with the portfolio weights that were estimated using equation (1) coupled with the observed returns of the matched hedge funds for period $\mathrm{T}+1$ :

$$
\hat{R}_{i, T+1}=\left[r_{L, T+1}\right] \hat{\beta}_{i}
$$

Now consider the situation where a hedge fund delists and does not report its return for period $\mathrm{T}+1$. We denote that unreported return as $r_{E, T+l}$. The econometrics and computations turn out to be much simpler if we base our estimates on matched FoF portfolios where there is a single delisting hedge fund. That situation represents approximately $89 \%$ of our matched sample, and we drop matches with multiple delisting hedge funds from the estimation procedure. Note that with one delisting fund in the portfolio, the vector of live returns $r_{L, T+1}$ will be one shorter than in the above situation where all hedge funds for a given FoF portfolio remained alive. In period $\mathrm{T}+1$, a FoF with a (single) delisting hedge fund in its portfolio will have an actual return that can be expressed as:

\footnotetext{
${ }^{8}$ There is a potential omitted variables problem in that a given FoF may be invested in one or more hedge funds that are not in our database. Our procedure implicitly approximates such missing funds by a linear combination of hedge funds that are in our database. Simulation studies discussed in Section IV below indicate our methodology works relatively well, even with a hypothetically large number of missing funds. As a practical matter, our combined database is large and should have a substantial portion of the relevant hedge funds, further mitigating the potential omitted variables problem.
} 


$$
R_{i, T+1}=\left[r_{L, T+1}, r_{E, T+1}\right] \beta_{i}+\varepsilon_{i, T+1}
$$

We approximate the true betas with the estimated betas from equation (1), and estimate the delisting return as:

$$
\hat{r}_{E, T+1}=\left(R_{i, T+1}-\left[r_{L, T+1}\right] \hat{\beta}_{L, i}\right) / \hat{\beta}_{E, i}, t=1, \ldots, T, \text { and } i=1, \ldots, N_{F o F},
$$

where $\hat{\beta}_{L, i}$ and $\hat{\beta}_{E, i}$ are the estimated betas respectively for the 14 hedge funds staying alive and the one delisting hedge fund in period $\mathrm{T}+1$ for the matched portfolio of $\mathrm{FoF}_{i}$. The numerator of equation (4) contains estimation error which is amplified when dividing by a fractional $\hat{\beta}_{E, i}$ (which is also estimated with error). Particularly when $\hat{\beta}_{E, i}$ is low, this calculation can result in large errors. We mitigate this problem by discarding matches where $\hat{\beta}_{E, i}<0.05$ as well as trimming (in each tail) the most extreme $1 \%$ of remaining estimates from equation (4).

We also consider the fact that several FoFs might invest in the same hedge fund. If that hedge fund delists, then the associated delisting return $r_{E, T+1}$ should be the same for all FoFs with that hedge fund in their portfolios. To ensure that result, we add up the relevant equations (3) while keeping the $r_{E, T+1}$ constant. The estimated realization of the delisting return in this case is:

$$
\hat{r}_{E, T+1}=\sum_{i}\left(R_{i, T+1}-\left[r_{L, T+1}\right] \hat{\beta}_{L, i}\right) / \sum_{i} \hat{\beta}_{E, i}, t=1, \ldots, T,
$$


where the sum is taken across all FoF matches i that include the delisted hedge fund of interest.

We estimate the mean delisting return by averaging the individual realizations calculated above. Our matching procedure does not require precise hedge fund identification, and the returns of funds truly included in a FoF portfolio can be proxied by returns of different (but correlated) funds in the matching portfolio. Nevertheless, the estimate of $\mu_{E}$ is unbiased only if a FoF truly invests into $k$ delisted hedge funds and the corresponding matched portfolio also has exactly $k$ delisted funds. One cannot guarantee that exact correspondence regarding the number of delisted funds while constructing the matching portfolios; and hence, we need to adjust the estimated $\mu_{E}$ for potential bias.

Since we use only matches that have exactly one delisted fund, the following biases can occur. First, consider a FoF that did not actually invest in any delisted fund; but the estimated matching portfolio erroneously contained a single delisted fund. Using this match, one would estimate not an unobserved delisting return (on average $\mu_{E}$ ) but the return of a hedge fund that was still alive. The higher the share of such matches, the more the estimated $\mu_{E}$ will be biased towards the average return of hedge funds that were reporting to the database, which we denote by $\mu_{H F}$. Second, if a FoF truly invested into one delisted hedge fund and the estimated matching portfolio also has one delisted fund, then the match has perfect correspondence and does not bias the estimate of $\mu_{E}$. Third, consider a FoF that actually had investments in two or more hedge funds that delisted; but that FoF was matched with a portfolio having only one delisted fund. If the number of truly delisted funds was two, the resulting average estimate would be $\mu_{E}+\left(\mu_{E}-\right.$ $\left.\mu_{H F}\right)$ instead of $\mu_{E}$. Simulation results described below indicate the probability is only $0.09 \%$ that a FoF with 3 or more truly delisting hedge funds is matched with a single delisting fund. 
Consequently, our adjustment procedure does not consider cases with three or more truly delisting hedge funds in a single FoF portfolio.

The biases due to the above mismatches can be corrected, if one knows the share of matches for each type. Let us denote by $p_{k}$ the probability that a FoF truly invested in $k$ delisted funds, and the estimated matching portfolio indicates the existence of only one delisted fund. Then the estimated biased delisting return $\mu_{E}^{\text {Estimated }}$ is a weighted average of the unbiased estimate $\mu_{E}$ Unbiased and the average return of hedge funds in the database $\mu_{H F .}{ }^{9}$ That is:

$$
\mu_{E}^{\text {Estimated }}=p_{0} \cdot \mu_{H F}+p_{1} \cdot \mu_{E}^{\text {Unbiased }}+\left(1-p_{0}-p_{1}\right) \cdot\left(2 \mu_{E}^{\text {Unbiased }}-\mu_{H F}\right)
$$

and we can solve for $\mu_{E}^{\text {Unbiased }}$

$$
\mu_{E}^{\text {Unbiased }}=\left[\mu_{E}^{\text {Estimated }}-\left(2 p_{0}+p_{1}-1\right) \cdot \mu_{H F}\right] /\left(2-2 p_{0}-p_{1}\right) .
$$

The probabilities $p_{k}$ are not known but can be estimated using a simulation procedure which is described in the appendix.

\section{Data Characteristics and Implementation}

We begin this section with a description of the data before proceeding to a discussion of our bootstrap procedure for estimating standard errors.

\footnotetext{
${ }^{9}$ In our adjustment, we use the average monthly return of all reporting hedge funds in the sample. This also include funds that were alive during a portion of the January 2000 - June 2009 period but eventually died.
} 


\section{A. The Data}

We have constructed a joint database using a union of six major databases (ALTVEST, BarclayHedge, CISDM, Eurekahedge, HFR, and TASS) from which we deleted duplicates and different share classes of the same fund. That joint database is large, containing more than 20,000 hedge funds and about 6,000 FoFs that reported sometime during the January 1994 - June 2009 period. Those funds are classified into dead and live hedge funds plus dead and live FoFs. We only use funds that report in US dollars and have a performance record after January 2000. This leaves us with 16,398 individual hedge funds and 5,031 FoFs. Panel A of Table 1 reports descriptive statistics for those funds over the period from January 2000 to June 2009. A fund being designated as live or dead in that table refers to its status as of June 2009. Note that the monthly returns are post-fee for both hedge funds and FoF in Panel A, just as they are reported in the database.

We eliminate the first 12 returns for each hedge fund in order to mitigate backfill bias. Our matching procedure requires funds which report returns for at least 36 consecutive months, and we eliminate all funds which do not satisfy that requirement (after deleting the first 12 monthly returns for hedge funds). Except for robustness tests discussed in Section IV, we only utilize FoFs which indicate they never use leverage.

When one looks at delisting events before January 2000, nearly half are reported as occurring at year end; however in many cases, the last several months of reported returns were all zeros. Thus, we believe that monthly delisting dates before January 2000 are not reliable. Consequently, we use only funds that report at least 36 returns after January 1997, such that their reported delisting occurs no earlier than January 2000. Panel B in Table 1 reports descriptive statistics for those funds; and we have 7,910 hedge funds, of which 3,194 delisted (died) at some time prior to the end of June 2009. Among the 1,348 FoFs in our restricted 
sample, 921 are classified as live funds; however, we can still use the 427 dead FoFs for windows of time when they were alive. For the FoF statistics in Panel B, we report pre-fee returns computed using the algorithm of Kolokolova (2011) mentioned previously. When implementing that algorithm, we use the reported fee structure for each FoF; however, as a point of information, the typical FoF in our data charges a management fee of $1 \%$ and an incentive fee of $10 \%$ per year.

\section{B. Bootstrapped Standard Errors}

Calculating standard errors for our analysis is potentially problematic due to the multiplelayer estimation procedure and the consequent accumulation of errors from the potential mismatch of FoF portfolios and the estimation of betas. Moreover, the different FoF matches will typically have overlapping time series. Because of these issues, we use a bootstrap approach to estimate standard errors. In particular, we utilize a two-stage procedure that bootstraps over the FoFs and the hedge funds. For the first stage, define a FoF instance to be a sequence of 37 returns for the relevant FoF. From the original data, we randomly draw with replacement the same number of FoF instances as in that original data to create a bootstrapped FoF instance set. In the second stage, we begin by identifying the set of hedge funds which provide 36 returns in parallel to the first 36 returns of a FoF instance. Some of these hedge funds have a $37^{\text {th }}$ return in parallel with the FoF instance, whereas others exit and have just the 36 returns. We then draw with replacement out of this set of hedge funds a bootstrapped hedge fund universe of the same size and potentially containing both live and exiting hedge funds. We use that bootstrapped hedge fund universe when we run our matching procedure for the associated FoF instance.

We employ our matching method with each FoF instance and its hedge fund universe in order to generate bootstrapped matches. This approach allows us to have bootstrapped matches 
which contain differing hedge funds as well as portfolio weights that differ from our original match. We obtain a new estimate for $\mu_{\mathrm{E}}$ using this bootstrapped set of matches and beta estimates. Finally, we use our bias correction described in the appendix to adjust for a mismatched number of delisting funds and obtain unbiased estimates for $\mu_{\mathrm{E}}$. We repeat this entire procedure 1,000 times to obtain bootstrapped standard errors which allow for potential mismatch of FoF portfolios, estimation error in the portfolio weights, overlapping time series, and small sample effects.

\section{[Insert Table 1 Near here]}

\section{Results}

The results discussed in this section are based on FoF matches using our standard procedure described above. For the entire initial set of matches, the average holdings of individual hedge funds $\left(\beta_{i}\right)$ are estimated to be 0.067 , with the standard deviation across matches of 0.033 . The average loadings on the delisting funds are estimated to be 0.062 , which increases to 0.087 after we discard matches where $\hat{\beta}_{E, i}<0.05$.

In Table 2, we report estimated mean delisting returns for "All" matches as well as for funds that stated they were being "Liquidated" or provided "No Reason" that was informative regarding their reason for delisting. ${ }^{10}$ For the set of All delisting hedge funds, we find an estimated average monthly delisting return (bias-corrected) of $-1.61 \%$. Although negative, that estimate is rather noisy and not significantly different from the average return for all hedge funds of $0.56 \%$ reported in Panel B of Table 1 . Moreover, this result is quite different from a very

10 Other self-reported categories such as "merged" and "closed to further investment" were too small to have reliable mean estimates. Among all delisted hedge funds, only $0.87 \%$ of funds report delisting because of being merged and some $2.08 \%$ because of being closed to further investment. 
large negative delisting return such as $-50 \%$; and the bootstrapped STD is such that we can be quite confident the average delisting firm does not have such a large negative delisting return. That conclusion is further supported by a simulation test reported in Section IV that indicates our procedure (albeit noisy) would reliably find a mean delisting return that was large and negative if the process generating the data had such a large negative mean.

\section{[Insert Table 2 Near Here]}

Turning to the Liquidated and No Reason fund categories considered separately, the situation changes. Funds in the No Reason category have a negative average delisting return of $-3.18 \%$, which is significantly different from the $0.56 \%$ average monthly return for all hedge funds with a p-value of 0.06 . The Liquidated funds have a positive estimated average delisting return of $2.69 \%$, which is significantly different from the estimate for No Reason funds (p-value of 0.06 ) but not significantly different from the average monthly return for all hedge funds. This pattern seems a bit surprising.

One tends to think that funds being liquidated were presumably poor performers and likely to have negative delisting returns rather than positive. In contrast, it seems plausible that the mean delisting return of funds that did not state a clear reason for delisting could be similar to the average monthly return of all (live) hedge funds. It might be that a substantial fraction of those No Reason funds were doing fairly well and delisted for other (unstated) reasons. Perhaps they merged or even were closed to further investment but did not bother to state that reason. Reporting to a database can be characterized as a form of advertising, and there could be a variety of reasons to stop advertising. Moreover, poor past performance should not necessarily indicate a 
negative delisting return if the fund's assets have been properly marked-to-market. Yet, we find a significantly negative average delisting return for the No Reason funds.

\section{A. Single Sorts}

To investigate this issue further, we sorted the exiting hedge funds into Top and Bottom groups, such that Top funds exhibit positive average returns over the six months prior to delisting, whereas Bottom funds exhibit negative average returns. Mean delisting returns for these sub-categories are reported in Table 3.

\section{[Insert Table 3 Near Here]}

There is evidence of return persistence, with the Top funds having higher mean delisting returns than the Bottom set of funds. The p-value of that difference for all funds is 0.05 . Top funds have a modestly positive mean delisting return of $0.31 \%$, whereas Bottom funds have a relatively large negative mean delisting return of $-4.25 \%$. The estimate for Bottom funds is significantly different from the average return of the all (live) hedge funds ( $p$-value 0.04). Note that the estimate for Bottom funds is quite large on an annualized basis, with $-4.25 \%$ monthly equating to $-51 \%$ annually (without compounding).

In identifying Top versus Bottom performing funds, we also used three alternative metrics: returns relative to the S\&P 500 and two measures of drawdown. We further define Top and Bottom in two ways; namely, with our usual cutoff (positive versus negative average returns over the six months prior to delisting) and alternatively with Top being the best $30 \%$ and Bottom being the worst $30 \%$ of hedge funds when assessed based on the above metrics. The results are very consistent across these different approaches, with the main message being that Bottom funds 
selected by a variety of plausible approaches have low delisting returns. Those results for Bottom funds are reported in Table 4.

\section{[Insert Table 4 Near Here]}

The persistence of poor results for Bottom funds is consistent with Getmansky, Lo, and Makarov (2004), who found persistence among live funds. Also, it is probable that some funds are exiting because their strategy and/or implementation is performing poorly in the then current economic environment. Most such funds would presumably be in the Bottom set; and assuming the environment continued to be unfavorable as they exited, return persistence seems reasonable. The negative mean delisting returns for both Bottom Liquidated and Bottom No Reason funds are consistent with that story; however, the result for Top Liquidated funds in Table 3 is somewhat counterintuitive. Return persistence itself is not surprising; but if a fund is apparently doing well, why is it being liquidated?

Looking at returns, we find positive average returns over the half-year prior to delisting of $1.18 \%$ per month for the Top Liquidated group and $1.38 \%$ per month for the Top No Reason group. So the average returns are positive but actually lower for the Top Liquidated group compared with the Top No Reason funds. The size of the Top Liquidated funds was on average a relatively small 57 million USD six months prior to delisting, compared with 123 million USD for the Top No Reason funds and 172 million USD for live funds with positive average returns over six-month periods. Also, the Top Liquidated funds had an average net outflow of 73 thousand USD per month during the 36 months prior to exit. In contrast, the Top No Reason group over the comparable period had an average inflow of 1.36 million USD per month (very similar to the average monthly inflow for all live funds of 1.30 million USD). This pattern 
suggests that Top Liquidated funds might have delisted because of their inability to attract enough capital, potentially not covering their fixed costs and almost certainly not generating the personal profits for which their managers had hoped.

We also looked at other characteristics of Liquidated and No Reason funds beyond the Top and Bottom classifications (based on positive or negative average returns for six months prior to delisting). We found that Liquidated funds have lower returns than No Reason funds during the previous 12 and 36-month periods (p-values of 0.01 and 0.00 , respectively). Furthermore, alpha based on the Fung and Hsieh (2004) model estimated over 36-month period is significantly lower for Liquidated funds, which would likely make it difficult to attract capital.

If we also use the Top and Bottom classification, we find Bottom Liquidated funds had an average monthly return of $-0.003 \%$ over the 3 years prior to liquidation. These funds were actually losing money on average for 3 years, and it's not surprising they decided to liquidate. The Top Liquidated funds did have positive average returns of $0.54 \%$ over the 36 months prior to liquidation but suffered from small size and weak fund flow as discussed above.

In contrast, both Top and Bottom No Reason funds had positive average monthly returns ( $0.77 \%$ and $0.24 \%$, respectively) over the 3 years prior to delisting. It seems likely that some of the Top No Reason funds were performing well, simply decided to "stop advertising," and had an unremarkable delisting return (not significantly different from the average return of a live fund). On the other hand, it may well be that many of the Bottom No Reason funds "blew up" and suddenly stopped reporting. Particularly for funds with illiquid positions, this would be consistent with the relatively large negative delisting returns we estimate for the Bottom No Reason group. Both these scenarios contrast with the Liquidated funds (both Top and Bottom), many of which appear to have been slowly strangling prior to announcing their liquidation. 


\section{B. Double Sorts}

Sorting on variables other than performance does not yield significant differences in delisting returns when we try off-shore vs. on-shore, audited vs. unaudited, fund size, fund flow, styles, leverage, fees, serial correlation, liquidity, and loadings on various Fung and Hsieh factors. These results are not too surprising as variables might be mis-measured or non-existing (e.g. Assets Under Management is not reported consistently by many funds), resulting subgroups turn out to be small, or variables might not be clearly related to performance (e.g. large positive as well as negative returns would both generate large variances).

We tried combining the above variables with past performance in economically sensible ways. Such double sorting can give us additional information about economically important variables but the significance may decline due to the smaller number of funds in each bin of the double-sort.

For example, it is reasonable to expect that hedge funds with positive past returns which also have relatively low volatility would have better delisting returns compared with hedge funds that historically had negative average returns and higher volatility. Indeed, we find such results when we consider Top funds with $30 \%$ lowest return volatility vs. bottom funds with $30 \%$ highest return volatility (p-value of 0.13 ). The results are reported in Panel A of Table 5.

In a similar vein, we tried separating out the best of the Top funds and worst of the Bottom funds based on estimated alpha over a longer (36 month) horizon. Alpha was estimated using the Fung and Hsieh 7-factor model over the preceding 36 months. Thus, we compare Top funds having high estimated alphas with Bottom funds having low estimated alphas. The results are in Panel B of Table 5. The added conditioning on alpha increases the difference between All Top and All Bottom average delisting returns compared with Table 3 (p-value of 0.06). 
Finally, we condition on being domiciled in the US or not. At least some off-shore hedge funds are presumably less regulated and more capable of exploiting profitable investment strategies (thus performing better). We double sort so that we compare off-shore, Top versus onshore, Bottom funds. The better No Reason funds outperform the worse No Reason funds in terms of delisting returns (p-value of 0.08), see Table 5, Panel C.

\section{[Insert Table 5 Near Here]}

\section{Robustness}

In this section we first evaluate the general quality of our matching algorithm, and then discuss the stability of our basic results to implementation changes in the estimation procedure.

\section{A. Quality of the matching algorithm}

We investigate the quality of our matching algorithm by constructing hypothetical FoF returns from reported hedge fund returns. The purpose of this exercise is to confirm that our procedure would find a large negative mean return if, in fact, that was the true situation. In other words, if the true mean delisting return were say $-50 \%$, our estimation procedure would deliver a similarly large negative mean estimate despite generating noisy return estimates. The simulation procedure we use here is almost identical to that described in the Appendix for estimating the probability of a mismatch regarding the number of delisting hedge funds in a FoF portfolio. The only difference is for delisting hedge funds, where we introduce a fictitious delisting return drawn from a Normal distribution with known mean and standard deviation.

We first consider a case, in which hedge fund delisting returns are rather similar to the returns of reporting funds. We simulate delisting returns with mean value of $1 \%$ and standard 
deviation of $5 \%$, which is roughly consistent with the mean of $0.56 \%$ and standard deviation of $4.55 \%$ for all hedge funds (Table 1, Panel B). Second, we simulate a case in which hedge funds incur moderately large losses upon delisting. The mean delisting return is shifted to $-10 \%$ while we keep the standard deviation unchanged at the $5 \%$ level. Last, we investigate a possible scenario with a dramatic mean delisting return of $-50 \%$ and a $10 \%$ standard deviation. We construct synthetic FoFs and repeat this exercise for as many sets of 36 consecutive FoF returns as we find in the actual data, each time moving forward by one month and then drawing hedge fund return vectors. Finally, we employ our usual estimation procedure to back out the mean delisting returns.

In implementing this test, we also consider the issue that our database does not contain all hedge funds. We do this by separating the hedge funds in our database into a "visible" set and an "invisible" set before generating the hypothetical FoF returns. That is, we split the database so that only a fraction $(100 \%, 67 \%$, or just $33 \%)$ of the total hedge funds will later be visible to our matching algorithm. For example, suppose we split the total so that $67 \%$ of the hedge funds are in the visible set and another $33 \%$ are invisible. We then generate each hypothetical FoF return by randomly drawing 10 hedge funds from the visible set and 5 funds from the invisible set. However when we implement the matching algorithm, it is only allowed to search for matches within the visible set.

From this new universe of hypothetical FoFs and selected hedge funds, we now proceed using our usual two-stage bootstrap procedure with 500 random samples. The estimated mean delisting returns based on the simulated FoFs are reported in Table 6. Those results indicate that our procedure does a good job of recovering large negative mean delisting returns of $-10 \%$ and $-50 \%$, and does not mistakenly find large negative mean returns when the true mean delisting return is $1 \%$. This is true even when only $33 \%$ of hedge funds in which the simulated FoFs 
invest are visible. ${ }^{11}$ Thus, we are rather confident that our procedure would not miss a large and negative mean delisting return even if the database only contained a modest fraction of the hedge fund universe.

\section{[Insert Table 6 Near Here]}

In situations (such as $-50 \%$ ) where the delisting return is very different from the average hedge fund results and some of the hedge funds held by the simulated FoFs are not in the visible data, our methodology tends to underestimate the absolute value of the delisting return. This is due to the algorithm not finding delisting hedge funds that are invisible (hidden) and instead erroneously including a live fund in the match. This is analogous to the mismatch problem described earlier and again biases the estimated mean delisting return toward the average monthly return for all hedge funds. Our combined database of 6 widely used commercial databases is large, and it should contain a substantial portion of the total hedge fund universe. Thus, we believe that the problem of seriously underestimating delisting returns because hedge funds are missing from the data is relatively minor in our study.

We recognize the possibility that a FoF alters its portfolio over time rather than holding it constant for 36 months. Such turnover behavior has implications for our methodology that are similar to a hedge fund not being included in the database. That is, our algorithm will tend to include spurious hedge funds in the estimated matches in an attempt to mimic the true timevarying holdings of the FoF. To examine potential implications of this problem, we implemented a simulation using a monthly turnover rate for all FoFs of $1.8 \%$ (equivalent to $20 \%$ annually,

\footnotetext{
11 See the Internet Appendix, Table IA.1 for results using a random match that also indicate our matching procedure performs quite well.
} 
which would correspond to roughly half of each FoF portfolio turning over in a three-year period). We create simulated FoF portfolios as previously (each with 15 hedge funds) except that none of the hedge funds will be treated as invisible. Then, each month with the probability $1.8 \%$ we substitute a randomly chosen new hedge fund for one in the current portfolio. For month 37 , one of the remaining hedge funds is designated as the delisting fund and its return is replaced by a randomly generated delisting return. We then implement our standard procedure to estimate the mean delisting return. If the delisting return was from a distribution with a mean of $1 \%$ and a standard deviation of $5 \%$, our procedure finds a mean return of $0.86 \%$. Even if the delisting return was from a distribution with a $-10 \%$ monthly mean return and a standard deviation of $5 \%$, or with a mean return of $-50 \%$ and a standard deviation of $10 \%$, the estimated mean delisting returns are also relatively accurate at $-7.68 \%$ and $-38.81 \%$ respectively. This suggests that the estimated mean delisting returns reported earlier in Table 2 are not very sensitive to the possibility of turnover in the FoF portfolios.

We also examined the accuracy of the matching algorithm and estimated portfolio weights by comparing the forecasted FoF portfolio return in the $37^{\text {th }}$ month with the actual FoF return in those matches where we have no delisting funds (consequently, having a full set of returns for the $37^{\text {th }}$ month). Our average forecast error is only $0.052 \%$ with a standard error of $1.76 \%$ for matches with R-squared above $25 \%$.

B. Stability of the empirical results

To assess result stability, we also implemented our procedure using variations on the basic methodology. Tables with results using these variations on our standard approach are provided in an Internet Appendix available from the authors. Most resulting changes relative to the estimated 
mean delisting returns reported in Table 2 are substantially less than one bootstrapped standard deviation from the original estimate, and we interpret them as minor differences.

The variations on our basic methodology included:

a. allowing investment in a riskless asset with a beta between 0.02 and 0.10 . Since the variability of the monthly riskless rate is very small, allowing investment in the riskless asset is also essentially equivalent to adding a constant term when estimating equation (1). Results are in Table IA.2

b. using rolling windows of 30 and 42 months in Table IA.3

c. altering the minimum beta limit to 0.01 and to 0.04 in Table IA. 4

d. increasing the maximum beta to 0.20 in Table IA.5

e. increasing the minimum $\mathrm{R}^{2}$ to 0.50 in Table IA.6

f. employing 0.05 as the trimming level for excluding outliers from the set of estimated delisting returns in Table IA.7

g. including only FoFs where we cannot reject the hypothesis of no serial correlation in returns at the $1 \%$ significance level in Table IA. 8 .

h. reducing the number of hedge funds in the FoF portfolio to a lower limit of 10 in Table IA.9

i. employing a procedure that allowed up to 26 hedge funds (an upper limit) in a match, where 26 corresponds to the average reported number in FoF portfolios for our data. Results are in Table IA.10

Another potential issue for our results concerns the possibility that a FoF manager identifies a hedge fund that seems likely to exit and seeks to unwind the FoF's position in that hedge fund before the exit takes place. From a practical perspective, lockups, gates, and notice periods all make it difficult for the FoF manager to quickly get out of a potentially exiting hedge 
fund. In the case of merged hedge funds or hedge funds closed to new investments, it might not even be desirable for the FoF to eliminate its positions in those funds. Moreover, predicting delisting is difficult. Thus, it is hard for FoFs to get out prior to an exit event. Nevertheless, we implemented a robustness check and re-estimated the delisting returns assuming that in month 37, the actual holding of a FoF in the delisting fund is half of the estimated weight (beta). In effect, we are assuming the FoF was successful in identifying the exiting hedge fund and was able to unwind half its position prior to the exit. That half of the estimated weight was equally distributed among the surviving hedge funds in that FoF portfolio. The mean delisting returns change very little (see Table IA.11), but their bootstrapped standard errors increase due to the smaller portfolio weight.

\section{Concluding Comments}

Relatively little has been known about returns after hedge funds delist from a database. We examine the situation by modeling the econometric relationship between funds of funds and the portfolios of hedge funds into which they invest. This structure allows us to estimate the average delisting return of $-1.61 \%$ for all delisting hedge funds, which is not significantly different from the $0.56 \%$ average monthly return for all (live) hedge funds. Our procedure for inferring FoF portfolio holdings is noisy; but with a large number of matches (nearly 1400 in Table 2) we obtain enough precision to have confidence in our average estimates. Thus, we have rather strong evidence that on average delisting returns are not a disastrously negative number such as $-50 \%$.

We also find that returns of delisting hedge funds are somewhat persistent. Hedge funds delisting after having positive average returns over the previous half-year also have positive average delisting returns of $0.31 \%$. Hedge funds delisting after a negative performance over the 
previous six months have a negative mean delisting return of $-4.25 \%$, which is significantly below $0.56 \%$ (average monthly return of all hedge funds) with a p-value of 0.04 . That $-4.25 \%$ mean return is also significantly (p-value of 0.05 ) below the $0.31 \%$ delisting return for funds with a positive average return over the previous six months. There is prior evidence on return persistence for live funds. So it is not surprising to find a continuation of that pattern to delisting returns; however, the persistence we find is significant only for the Bottom performing funds.

Examining that result more closely, we divided funds with negative performance over the previous six months into those which also stated they were being liquidated (Bottom Liquidated) and those which did not provide a clear reason for exiting (Bottom No Reason). The Bottom Liquidated funds had an unremarkable mean delisting return of $-0.59 \%$, but the Bottom No Reason funds had a strongly negative delisting return of $-5.97 \%$, which is significantly below $0.56 \%$ (average monthly return of all hedge funds) with a p-value of 0.01 . It seems likely that many of the Bottom No Reason funds may have been forced to exit suddenly under adverse circumstances.

It is straightforward that funds with negative prior returns might decide to delist, but why are a substantial number of Top funds with positive returns also opting to exit? We drilled deeper into this issue and found that funds with positive six-month returns which state they were being liquidated had a relatively large mean delisting return of $5.46 \%$. However, this mean estimate for Top Liquidated funds in Table 3 also has a relatively large bootstrapped STD of $2.35 \%$ and, consequently, is not significantly greater than the average monthly return for all hedge funds.

One tends to think that funds are liquidated because of poor performance, and this result seems inconsistent with that view. However, those funds are small with average assets under management less than 60 million USD as opposed to 172 million USD for the average live hedge fund with positive returns over a six-month period. Furthermore, they have also been 
experiencing weak fund flow (an average outflow of 73 thousand USD per month over the three years prior to delisting). It seems plausible that the Top Liquidators are a set of small funds that did not perform well enough to attract substantial inflows and achieve a critical mass, where they became sufficiently profitable for their managers. Hence after struggling for a time, those managers may simply have opted to liquidate the funds and move on to more promising endeavors.

In summary, we find that most exiting funds are in categories which have mean delisting returns that are not significantly different from the average monthly return of live hedge funds. In marked contrast, Bottom No Reason funds have a mean delisting return $(-5.97 \%)$ which is significantly below the mean delisting returns of other categories as well as being significantly below the average monthly return for live funds. 


\section{Appendix: Adjusting for the Potential Mismatch Bias}

To correct a potential bias from a mismatch indicating the wrong number of delisting funds in a FoF portfolio, we need an estimate of $p_{k}$ (the probability that there were truly $\mathrm{k}$ delisting funds in that portfolio when the estimated match indicates one delisting fund). We estimate those $p_{k}$ probabilities using simulation. First, we construct hypothetical FoFs from existing hedge funds. For each FoF portfolio, we randomly draw without replacement a hedge fund and its vector of consecutive returns from the hedge fund database. If that hedge fund remains alive, it will have a vector of 37 consecutive returns. If it is a delisting fund, the vector will have 36 consecutive returns with delisting occurring in month 37 . Repeating this procedure, we construct the same number of FoFs for each consecutive 36 months as the true number of FoFs reporting to our database during this period. Each constructed FoF consists of 15 such randomly drawn hedge funds, and we flag which hedge funds in a simulated FoF actually delisted. The portfolio weights are uniformly and randomly selected in the interval 0.02 to 0.10 and are required to sum up to one. ${ }^{12}$

We then move forward by one month in time and repeat this exercise, continuing in this manner until we cover the complete time frame of available data. We next employ our usual matching procedure. Based on those estimated matches, we compute the frequencies for matches in which one estimated delisting fund (using our matching procedure) corresponds to $0,1,2$, and 3 or more true delistings in the simulated FoFs. We repeat the complete simulation 100 times and compute the estimated probabilities $p_{k}$ as averages of the corresponding frequencies. Table A.1 below reports the characteristics of the estimated probabilities.

\footnotetext{
12 We use a classical acceptance-rejection algorithm here, in which we uniformly and randomly select 14 portfolio weights from a closed interval $[0.02,0.10]$ and compute the $15^{\text {th }}$ portfolio weight as a difference between unity and the sum of the previously obtained 14 weights. We accept this vector of portfolio weights if the last computed weight also lies between 0.02 and 0.10 , and reject it otherwise.
} 


\section{[Table A.1 about here]}

The standard deviations of the simulated probabilities are rather small, and we use the mean probability values for the bias correction. 


\section{References}

Ackermann, Carl, Richard McEnally, and David Ravenscraft, 1999, The Performance of Hedge Funds, Journal of Finance 54, No. 1, 833-874.

Agarwal, Vikas, Naveen D. Daniel, and Narayan Y. Naik, 2009, Role of managerial incentives and discretion in hedge fund performance, Journal of Finance 64, No. 5, 2221-2256.

Agarwal, Vikas, Vyacheslav Fos, and Wei Jiang, 2010, Inferring Reporting Biases in Hedge Fund Databases from Hedge Fund Equity Holdings, Working Paper, Georgia State University, SSRN=1536886.

Aiken, Adam L., Christopher P. Clifford, and Jesse Ellis, 2010, Out of the dark: Hedge fund reporting biases and commercial databases, Working Paper, University of Kentucky, $\mathrm{SSRN}=1519914$.

Brooks, Chris, Andrew Clare, and Nick Motson, 2008, The Gross Truth about Hedge Fund Performance and Risk: The Impact of Incentive Fees, Journal of Financial Transformation 24, .33-42.

Brown, S. J., W. N. Goetzmann, and R. G. Ibbotson, 1999, Offshore Hedge Funds: Survival and Performance, 1989-95, Journal of Business 72, No. 1, 91-117.

Fung, William, and David A. Hsieh, 2000, Performance Characteristics of Hedge Funds and CTA Funds: Natural Versus Spurious Biases, Journal of Financial and Quantitative Analysis 35, No. 3, 291-307.

Fung, William, and David A. Hsieh, 2004, Hedge Fund Benchmarks: A Risk Based Approach, Financial Analyst Journal 60, No. 5, 65-80.

Fung, William, David A. Hsieh, Narayan Y. Naik, and Tarun Ramadorai, 2008, Hedge Funds: Performance, Risk, and Capital Formation, Journal of Finance 63, No. 4, 1777-1803. 
Getmansky, Mila, Andrew W. Lo, and Igor Makarov, 2004, An econometric model of serial correlation and illiquidity in hedge fund returns, Journal of Financial Economics 74, No. 3, 529-610.

ter Horst, Jenke, and Marno Verbeek, 2007, Fund liquidation, Self-selection and Look-ahead Bias in the Hedge Fund Industry, Review of Finance 11, No. 4, 605-632.

Kolokolova, Olga, 2011, "Strategic Behavior within Families of Hedge Funds," Journal of Banking and Finance 35, No. 7, 1645-1662.

Liang, Bing, 2000, Hedge Funds: The Living and the Dead, Journal of Financial and Quantitative Analysis 35, No. 3, 309-326.

Liang, Bing, and Hyuna Park, 2010, Predicting Hedge Fund Failure: A Comparison of Risk Measures, Journal of Financial and Quantitative Analysis 45, No. 1, 199-222.

Posthuma, Nolke, and Pieter Jelle van der Sluis, 2004, A Critical Examination of Historical Hedge Fund Returns, Chapter 13 in Intelligent Hedge Fund Investing: Successfully Avoiding Pitfalls through Better Risk Evaluation, edited by Barry Schachter, Risk Books.

Van, George P., and Zhiyi Song, 2005, Hedge Fund Commentary from VAN, Working Paper, Van Hedge Fund Advisors International, www.edge-fund.com/VanSong2005.pdf 


\section{Table 1: Descriptive Statistics}

The table reports descriptive statistics for funds from the union of six databases (ALTVEST, BarclayHedge, CISDM, Eurekahedge, HFR, and TASS). Panel A is based on all unique funds reporting in US dollars during January 2000 - June 2009. Panel B is based on the funds used in our analysis, after we dropped the first 12 observations for all hedge funds and eliminated any hedge fund and FoF that did not have at least 36 consecutive remaining observations between January 1997 and June 2009. The performance of these funds is reported between January 2000 and June 2009. We also eliminate FoFs that report using leverage. Return statistics are based on monthly returns in percent. Note that all returns in Panel A are post-fee. In Panel B, the FoF returns are grossed up to a pre-fee basis, while the hedge-fund returns remain post-fee. All values except Number of Funds are averages of the corresponding statistics for the individual funds.

\begin{tabular}{l|ccc|ccc} 
& \multicolumn{6}{c}{ Panel A: All Funds Jan. $2000-$ Jun. 2009} \\
& \multicolumn{3}{|c}{ All } & Ledge Funds, post-fee & \multicolumn{3}{c}{ Funds of Funds, post-fee } \\
& 16398 & 8847 & 7551 & 5031 & 3625 & 1406 \\
\hline Number & 3.27 & 4.72 & 2.00 & 4.12 & 4.82 & 2.53 \\
Life Time in Years & 0.55 & 0.70 & 0.37 & 0.25 & 0.22 & 0.31 \\
Mean Return & 0.50 & 0.79 & 0.16 & 0.46 & 0.51 & 0.34 \\
Median Return & 4.60 & 4.33 & 4.92 & 2.45 & 2.48 & 2.37 \\
STD & -10.18 & -11.01 & -9.21 & -6.71 & -7.34 & -5.09 \\
Min Return & 11.68 & 11.78 & 11.56 & 5.32 & 5.27 & 5.45 \\
Max Return & -0.07 & -0.22 & 0.11 & -0.63 & -0.81 & -0.18 \\
Skewness & 5.04 & 5.71 & 4.25 & 5.56 & 5.97 & 4.47 \\
Kurtosis & 0.14 & 0.22 & 0.05 & 0.13 & 0.12 & 0.16 \\
Sharpe Ratio & & & & & Lead & \\
\hline
\end{tabular}

Panel B: Funds with at least 36 Returns Jan. 2000 - Jun. 2009

\begin{tabular}{l|ccc|ccc}
\hline & \multicolumn{5}{c}{ Panel B: Funds with at least 36 Returns Jan. 2000 - Jun. 2009 } \\
& \multicolumn{3}{|c}{ Hedge Funds, post-fee } & \multicolumn{3}{c}{ Funds of Funds, pre-fee, no leverage } \\
& All & Live & Dead & All & Live & Dead \\
\hline Number & 7910 & 4716 & 3194 & 1348 & 921 & 427 \\
Life Time in Years & 5.37 & 6.44 & 3.81 & 5.56 & 6.33 & 3.91 \\
Mean Return & 0.56 & 0.75 & 0.26 & 0.56 & 0.62 & 0.45 \\
Median Return & 0.51 & 0.84 & 0.02 & 0.71 & 0.84 & 0.41 \\
STD & 4.55 & 4.17 & 5.11 & 2.54 & 2.46 & 2.72 \\
Min Return & -11.66 & -12.19 & -10.87 & -7.51 & -8.06 & -6.32 \\
Max Return & 13.34 & 13.06 & 13.74 & 6.92 & 6.71 & 7.38 \\
Skewness & -0.08 & -0.26 & 0.18 & -0.54 & -0.77 & -0.04 \\
Kurtosis & 6.00 & 6.67 & 4.99 & 6.65 & 7.17 & 5.52 \\
Sharpe Ratio & 0.11 & 0.17 & 0.04 & 0.20 & 0.20 & 0.20
\end{tabular}




\section{Table 2: Mean Delisting Returns}

We report the monthly delisting returns (bias-corrected) based on matched portfolios of FoFs where the adjusted R-squared of the main regression model is at least $25 \%$ and the portfolio weight of the delisting fund is at least $5 \%$. We use $1 \%$ tail trimming. Mean delisting returns and their standard deviations are in \% per month.

\begin{tabular}{lcccc} 
& $\begin{array}{c}\text { Number of } \\
\text { Matches }\end{array}$ & $\begin{array}{c}\text { Mean } \\
\text { Delisting } \\
\text { Return }\end{array}$ & $\begin{array}{c}\text { Bootstrapped } \\
\text { STD of Mean } \\
\text { Delisting } \\
\text { Return }\end{array}$ & $\begin{array}{c}\text { Non-parametric } \\
\text { p-value for } \\
\text { difference with } \\
\text { average HF return }\end{array}$ \\
\hline All & 1392 & -1.61 & 0.94 & 0.16 \\
\hline Liquidated & 358 & 2.69 & 1.75 & 0.23 \\
No Reason & 998 & -3.18 & 1.09 & 0.06 \\
\hline
\end{tabular}


Table 3: Mean Delisting Returns: Top vs. Bottom

We report the monthly delisting returns (bias-corrected) based on matched portfolios of FoFs where the adjusted R-squared of the main regression model is at least $25 \%$ and the portfolio weight of the delisting fund is at least $5 \%$. We use $1 \%$ tail trimming. Mean delisting returns and their standard deviations are in $\%$ per month. Top (Bottom) funds have positive (negative) average returns over the 6 months prior to the delisting event.

\begin{tabular}{lccccc} 
& $\begin{array}{c}\text { Number } \\
\text { of } \\
\text { Matches }\end{array}$ & $\begin{array}{c}\text { Mean } \\
\text { Delisting } \\
\text { Return }\end{array}$ & $\begin{array}{c}\text { Bootstrapped } \\
\text { STD of Mean } \\
\text { Delisting Return }\end{array}$ & $\begin{array}{c}\text { Non-parametric } \\
\text { p-value for } \\
\text { difference with } \\
\text { average HF return }\end{array}$ & $\begin{array}{c}\text { Non-parametric } p \text { - } \\
\text { value for the } \\
\text { difference between } \\
\text { Top and Bottom } \\
\text { Funds }\end{array}$ \\
\hline All & 807 & 0.31 & 1.17 & 0.38 & 0.05 \\
\hline Liquidated & 194 & 5.46 & 2.35 & 0.16 & 0.27 \\
No Reason & 593 & -1.28 & 1.29 & 0.43 & 0.05 \\
\hline All & & & Bottom & & - \\
\hline Liquidated & 164 & -0.59 & 1.42 & 0.04 & -- \\
No Reason & 405 & -5.97 & 1.77 & 0.44 & --
\end{tabular}


Table 4: Mean Delisting Returns of Bottom Funds Selected by Alternative Metrics We report the monthly delisting returns (bias-corrected) based on matched portfolios of FoFs where the adjusted R-squared of the main regression model is at least $25 \%$ and the portfolio weight of the delisting fund is at least 5\%. We use $1 \%$ tail trimming. Mean delisting returns and their standard deviations are in $\%$ per month. We use several ways to define Bottom funds, which are described in the first column.

\begin{tabular}{|c|c|c|c|c|}
\hline Bottom Funds & $\begin{array}{l}\text { Number } \\
\text { of } \\
\text { Matches }\end{array}$ & $\begin{array}{l}\text { Mean } \\
\text { Delisting } \\
\text { Return }\end{array}$ & $\begin{array}{l}\text { Bootstrapped } \\
\text { STD of Mean } \\
\text { Delisting Return }\end{array}$ & $\begin{array}{c}\text { Non-parametric } \\
p \text {-value for } \\
\text { difference with } \\
\text { average HF return }\end{array}$ \\
\hline Negative average 6-month return & 585 & -4.25 & 1.42 & 0.04 \\
\hline $30 \%$ lowest average 6 -month return & 427 & -3.60 & 1.71 & 0.06 \\
\hline $\begin{array}{l}\text { Average 6-month return below the } \\
\text { corresponding return on the S\&P500 } \\
\text { index }\end{array}$ & 576 & -3.76 & 1.42 & 0.04 \\
\hline $\begin{array}{l}30 \% \text { largest difference in the } 6 \text {-month } \\
\text { fund return and the return on the } \\
\text { S\&P500 index }\end{array}$ & 397 & -3.95 & 1.62 & 0.06 \\
\hline $\begin{array}{l}\text { Drawdown based on the highest to } \\
\text { lowest fund NAV is below the median }\end{array}$ & 786 & -2.84 & 1.26 & 0.06 \\
\hline $\begin{array}{l}30 \% \text { largest drawdown based on the } \\
\text { highest to lowest fund NAV }\end{array}$ & 442 & -2.79 & 1.89 & 0.13 \\
\hline $\begin{array}{l}\text { Drawdown based on the highest to last } \\
\text { fund NAV is below the median }\end{array}$ & 789 & -3.08 & 1.26 & 0.06 \\
\hline $\begin{array}{l}30 \% \text { largest drawdown based on the } \\
\text { highest to last fund NAV }\end{array}$ & 439 & -3.34 & 1.86 & 0.08 \\
\hline
\end{tabular}


Table 5: Mean Delisting Returns: Top vs. Bottom Funds with Double-Sorts

We report the monthly delisting returns (bias-corrected) based on matched portfolios of FoFs where the adjusted R-squared of the main regression model is at least $25 \%$ and the portfolio weight of the delisting fund is at least $5 \%$. We use $1 \%$ tail trimming. Mean delisting returns and their standard deviations are in $\%$ per month. Panel A reports the results for Top funds having low return volatility and Bottom funds having high return volatility. Panel B reports the results for Top funds having high estimated alpha based on the Hung and Hsieh (2004) sevenfactor model and Bottom funds having low estimated alphas. Panel $\mathrm{C}$ reports the results for Top off-shore funds and Bottom on-shore funds.

\begin{tabular}{|c|c|c|c|c|c|}
\hline & $\begin{array}{l}\text { Number } \\
\text { of } \\
\text { Matches }\end{array}$ & $\begin{array}{l}\text { Mean } \\
\text { Delisting } \\
\text { Return }\end{array}$ & $\begin{array}{l}\text { Bootstrapped } \\
\text { STD of Mean } \\
\text { Delisting Return }\end{array}$ & $\begin{array}{c}\text { Non-parametric } \\
\text { p-value for } \\
\text { difference with } \\
\text { average HF return }\end{array}$ & $\begin{array}{l}\text { Non-parametric p- } \\
\text { value for the } \\
\text { difference between } \\
\text { Top and Bottom } \\
\text { Funds }\end{array}$ \\
\hline \multicolumn{6}{|c|}{ Panel A } \\
\hline \multicolumn{6}{|c|}{ Top, $30 \%$ Lowest Return STD } \\
\hline All & 298 & 0.42 & 1.47 & 0.49 & 0.13 \\
\hline Liquidated & 70 & 4.47 & 3.20 & 0.21 & 0.37 \\
\hline No Reason & 220 & -0.89 & 1.70 & 0.30 & 0.13 \\
\hline \multicolumn{6}{|c|}{ Bottom, 30\% Highest Return STD } \\
\hline All & 243 & -5.43 & 2.52 & 0.09 & -- \\
\hline Liquidated & 59 & -2.10 & 4.56 & 0.42 & -- \\
\hline No Reason & 176 & -6.74 & 2.97 & 0.06 & -- \\
\hline \multicolumn{6}{|c|}{ Panel B } \\
\hline \multicolumn{6}{|c|}{ Top, $30 \%$ Highest Alphas } \\
\hline All & 303 & 2.17 & 2.01 & 0.24 & 0.06 \\
\hline Liquidated & 60 & 4.36 & 4.43 & 0.26 & 0.26 \\
\hline No Reason & 230 & 2.24 & 2.28 & 0.28 & 0.06 \\
\hline \multicolumn{6}{|c|}{ Bottom, 30\% Lowest Alphas } \\
\hline All & 254 & -6.28 & 2.31 & 0.08 & -- \\
\hline Liquidated & 69 & -2.96 & 4.10 & 0.38 & -- \\
\hline No Reason & 179 & -7.63 & 2.86 & 0.07 & -- \\
\hline \multicolumn{6}{|c|}{ Panel C } \\
\hline \multicolumn{6}{|c|}{ Top, Off-Shore } \\
\hline All & 386 & 1.99 & 1.58 & 0.26 & 0.12 \\
\hline Liquidated & 116 & 4.91 & 3.02 & 0.26 & 0.50 \\
\hline No Reason & 259 & 0.72 & 1.81 & 0.36 & 0.08 \\
\hline \multicolumn{6}{|c|}{ Bottom, On-Shore } \\
\hline All & 274 & -4.79 & 2.14 & 0.15 & -- \\
\hline Liquidated & 50 & 4.91 & 4.40 & 0.32 & -- \\
\hline No Reason & 216 & -7.37 & 2.46 & 0.08 & -- \\
\hline
\end{tabular}




\section{Table 6: Simulated Performance Results}

The table reports mean delisting returns as well as the bootstrapped standard deviations of the mean delisting return for simulated samples of FoF returns. Each FoF is modeled as a portfolio of 15 individual hedge funds. For simulated delisting funds, the hypothetical delisting return is drawn from a normal distribution with given mean $\left(\mu_{E}\right)$ and standard deviation $\left(\sigma_{E}\right)$, expressed in percent per month. The reported estimates are obtained using our standard procedure with a subset of the hedge funds used to generate the FoF returns being visible to our matching algorithm. We vary the fraction of visible funds using $100 \%, 67 \%$, and $33 \%$ of the total generating set. We consider three possible delisting return distributions for hedge funds, characterized by pairs $\left(\mu_{E}, \sigma_{E}\right)$ of $(1,5),(-10,5)$, and $(-50,10)$. Values are in $\%$ per month.

\begin{tabular}{cccc}
$\begin{array}{c}\text { Number of } \\
\text { Visible Funds }\end{array}$ & $\begin{array}{c}\text { Number of } \\
\text { Matches }\end{array}$ & $\begin{array}{c}\text { Mean Delisting } \\
\text { Return }\end{array}$ & $\begin{array}{c}\text { Bootstrapped STD of } \\
\text { Mean Delisting Return }\end{array}$ \\
\hline \multicolumn{5}{c}{$\left(\mu_{E}, \sigma_{E}\right)=(1,5)$} & \\
\hline 15 & 2590 & -0.05 & 0.48 \\
10 & 1935 & 1.12 & 0.68 \\
5 & 1035 & -0.71 & 0.52 \\
\hline 15 & & $\left(\mu_{E}, \sigma_{E}\right)=(-10,5)$ & \\
\hline 10 & 2574 & -8.43 & 0.51 \\
5 & 1914 & -8.94 & 0.54 \\
& 1005 & -6.34 & 0.54 \\
\hline 15 & & $\left(\mu_{E}, \sigma_{E}\right)=(-50,10)$ & \\
10 & 2576 & -39.84 & 0.89 \\
5 & 1884 & -38.66 & 0.91 \\
\hline & 1033 & -33.62 & 0.96 \\
\hline
\end{tabular}


Table A.1: Estimated Probabilities for Delisting Mismatches of Different Types The table reports the estimated probabilities, via simulation, that the true FoF invests into 0,1 , 2 , and 3 or more delisting hedge funds when the estimated matching portfolio includes exactly one delisting hedge fund with the corresponding portfolio weight being at least $5 \%$.

\begin{tabular}{c|cccc}
$\begin{array}{c}\text { Number of delisted } \\
\text { funds in true FoF (k) }\end{array}$ & 0 & 1 & 2 & 3 or more \\
\hline Mean Probability (\%) & 59.97 & 37.64 & 2.30 & 0.09 \\
STD Probability (\%) & 0.80 & 0.85 & 0.27 & 0.06
\end{tabular}




\section{Internet Appendix}

Table IA.1: Simulated Performance Results Using a Random Match

The table reports mean delisting returns as well as the bootstrapped standard deviations of the mean delisting return for simulated samples of FoF returns. Each FoF is modeled as a portfolio of 15 individual hedge funds. For simulated delisting funds, the hypothetical delisting return is drawn from a normal distribution with given mean $\left(\mu_{E}\right)$ and standard deviation $\left(\sigma_{E}\right)$, expressed in percent per month. The reported estimates are obtained by random assignment of 15 hedge funds to a FoF portfolio. We consider three possible delisting return distributions for hedge funds, characterized by pairs $\left(\mu_{E}, \sigma_{E}\right)$ of $(1,5),(-10,5)$, and $(-50,10)$. Values are in $\%$ per month.

\begin{tabular}{cccc}
$\begin{array}{c}\text { Number of Visible } \\
\text { Funds }\end{array}$ & $\begin{array}{c}\text { Number of } \\
\text { Matches }\end{array}$ & $\begin{array}{c}\text { Mean Delisting } \\
\text { Return }\end{array}$ & $\begin{array}{c}\text { Bootstrapped STD of } \\
\text { Mean Delisting Return }\end{array}$ \\
\hline & & & \\
\hline$\left(\mu_{E}, \sigma_{E}\right)=(1,5)$ & 2674 & 0.54 & 0.58 \\
$\left(\mu_{E}, \sigma_{E}\right)=(-10,5)$ & 2687 & -3.58 & 0.58 \\
$\left(\mu_{E}, \sigma_{E}\right)=(-50,10)$ & 2667 & -18.61 & 0.80 \\
\hline
\end{tabular}




\section{Table IA.2: Mean Delisting Returns with a Risk-Free Investment}

We report the monthly delisting returns (bias-corrected) based on matched portfolios of FoFs allowing investment in a riskless asset with a beta between 0.02 and 0.10 where the adjusted Rsquared of the main regression model is at least $25 \%$ and the portfolio weight of the delisting fund is at least $5 \%$. We use $1 \%$ tail trimming. Mean delisting returns and their standard deviations are in $\%$ per month.

\begin{tabular}{lccccc} 
& $\begin{array}{c}\text { Number of } \\
\text { Matches }\end{array}$ & $\begin{array}{c}\text { Mean } \\
\text { Delisting } \\
\text { Return }\end{array}$ & $\begin{array}{c}\text { Bootstrapped } \\
\text { STD of Mean } \\
\text { Delisting } \\
\text { Return }\end{array}$ & $\begin{array}{c}\text { Non-parametric } \\
\text { p-value for } \\
\text { difference with } \\
\text { average HF return }\end{array}$ & $\begin{array}{c}\text { Absolute change } \\
\text { with respect to the } \\
\text { main results } \\
\text { expressed as a } \\
\text { number of standard } \\
\text { deviations of the } \\
\text { main results }\end{array}$ \\
\hline All & 1393 & -1.70 & 0.97 & 0.15 & 0.10 \\
\hline Liquidated & 358 & 2.58 & 1.75 & 0.23 & 0.06 \\
No Reason & 999 & -3.28 & 1.13 & 0.05 & 0.09 \\
\hline
\end{tabular}




\section{Table IA.3: Mean Delisting Returns with Different Lengths of the Estimation Period}

We report the monthly delisting returns (bias-corrected) based on matched portfolios of FoFs where the adjusted R-squared of the main regression model is at least $25 \%$ and the portfolio weight of the delisting fund is at least $5 \%$. We use $1 \%$ tail trimming. Mean delisting returns and their standard deviations are in \% per month. Panel A is based on a 30 month rolling window, panel B is based on a 42 month rolling window.

$\begin{array}{ccc}\begin{array}{c}\text { Number of } \\ \text { Matches }\end{array} & \begin{array}{c}\text { Mean } \\ \text { Delisting } \\ \text { Return }\end{array} & \begin{array}{c}\text { Bootstrapped } \\ \text { STD of Mean } \\ \text { Delisting } \\ \text { Return }\end{array}\end{array}$

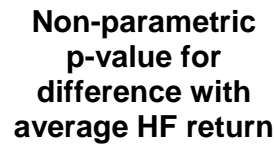

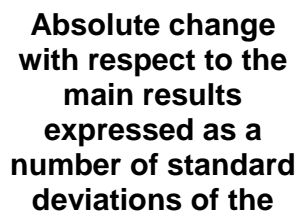

Absolute change with respect to the main results expressed as a number of standard deviations of the main results

\begin{tabular}{lccccc}
\hline \multicolumn{7}{c}{ Panel A: 30 month rolling window } \\
\hline All & 1481 & -0.57 & 0.94 & 0.19 & 1.11 \\
\hline Liquidated & 376 & -1.94 & 1.74 & 0.32 & 2.64 \\
No Reason & 1063 & 0.32 & 1.09 & 0.14 & 3.22 \\
\hline \multicolumn{7}{c}{ Panel B: } & 42 month rolling window \\
\hline All & 1226 & -1.16 & 0.95 & 0.09 & 0.47 \\
\hline Liquidated & 300 & 1.68 & 1.83 & 0.37 & 0.58 \\
No Reason & 895 & -2.20 & 1.09 & 0.03 & 0.90 \\
\hline
\end{tabular}


Table IA.4: Mean Delisting Returns with Different Minimum Portfolio Weights

We report the monthly delisting returns (bias-corrected) based on matched portfolios of FoFs where the adjusted R-squared of the main regression model is at least $25 \%$ and the portfolio weight of the delisting fund is at least $5 \%$. We use $1 \%$ tail trimming. Mean delisting returns and their standard deviations are in \% per month. In panel $\mathrm{A}$, the minimum portfolio weight in a FoF portfolio is 0.01 . In panel $\mathrm{B}$, the minimum weight is 0.04 .

\begin{tabular}{lccccc} 
& $\begin{array}{c}\text { Number of } \\
\text { Matches }\end{array}$ & $\begin{array}{c}\text { Mean } \\
\text { Delisting } \\
\text { Return }\end{array}$ & $\begin{array}{c}\text { Bootstrapped } \\
\text { STD of Mean } \\
\text { Delisting } \\
\text { Return }\end{array}$ & $\begin{array}{c}\text { Non-parametric } \\
\text { p-value for } \\
\text { difference with } \\
\text { average HF return }\end{array}$ & $\begin{array}{c}\text { Absolute change } \\
\text { with respect to the } \\
\text { main results } \\
\text { expressed as a } \\
\text { number of standard } \\
\text { deviations of the } \\
\text { main results }\end{array}$ \\
\hline All & 1407 & -1.61 & 0.94 & 0.18 & 0.00 \\
\hline Liquidated & 362 & 2.39 & 1.73 & 0.21 & 0.17 \\
No Reason & 1006 & -3.08 & 1.07 & 0.07 & 0.10 \\
\hline & & Panel B: Minimum portfolio weight 0.04 & 0.17 \\
\hline All & 1336 & -1.45 & 0.99 & 0.10 & 0.96 \\
\hline Liquidated & 346 & 1.00 & 1.96 & 0.34 & 0.92 \\
No Reason & 957 & -2.18 & 1.19 & 0.04 & 0.01 \\
\hline
\end{tabular}


Table IA.5: Mean Delisting Returns with a Maximum Portfolio Weight of 0.20

We report the monthly delisting returns (bias-corrected) based on matched portfolios of FoFs where the adjusted R-squared of the main regression model is at least $25 \%$ and the portfolio weight of the delisting fund is at least $5 \%$. We use $1 \%$ tail trimming. Mean delisting returns and their standard deviations are in $\%$ per month. The maximum portfolio weight in a FoF portfolio is 0.20 .

$$
\begin{array}{ccc}
\begin{array}{c}
\text { Number of } \\
\text { Matches }
\end{array} & \begin{array}{c}
\text { Mean } \\
\text { Delisting } \\
\text { Return }
\end{array} & \begin{array}{c}
\text { Bootstrapped } \\
\text { STD of Mean } \\
\text { Delisting }
\end{array}
\end{array}
$$

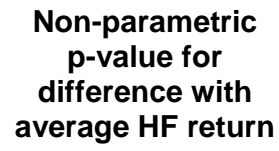

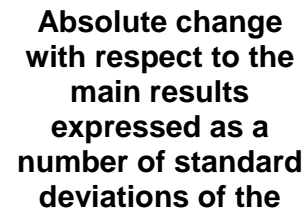

Absolute change with respect to the main results expressed as a number of standard deviations of the main results

\begin{tabular}{lccccc}
\hline All & 1190 & -1.07 & 0.98 & 0.28 & 0.57 \\
\hline Liquidated & 301 & 1.07 & 1.66 & 0.21 & 0.92 \\
No Reason & 860 & -1.82 & 1.17 & 0.14 & 1.25 \\
\hline
\end{tabular}


Table IA.6: Mean Delisting Returns with an adjusted R-squared of at least $\mathbf{5 0 \%}$ We report the monthly delisting returns (bias-corrected) based on matched portfolios of FoFs where the adjusted R-squared of the main regression model is at least $50 \%$ and the portfolio weight of the delisting fund is at least $5 \%$. We use $1 \%$ tail trimming. Mean delisting returns and their standard deviations are in \% per month.

\begin{tabular}{lccccc} 
& $\begin{array}{c}\text { Number of } \\
\text { Matches }\end{array}$ & $\begin{array}{c}\text { Mean } \\
\text { Delisting } \\
\text { Return }\end{array}$ & $\begin{array}{c}\text { Bootstrapped } \\
\text { STD of Mean } \\
\text { Delisting } \\
\text { Return }\end{array}$ & $\begin{array}{c}\text { Non-parametric } \\
\text { p-value for } \\
\text { difference with } \\
\text { average HF return }\end{array}$ & $\begin{array}{c}\text { Absolute change } \\
\text { with respect to the } \\
\text { main results } \\
\text { expressed as a } \\
\text { number of standard } \\
\text { deviations of the } \\
\text { main results }\end{array}$ \\
\hline All & 1381 & -1.16 & 0.93 & 0.19 & 0.48 \\
\hline Liquidated & 354 & 3.12 & 1.74 & 0.23 & 0.24 \\
No Reason & 991 & -2.70 & 1.08 & 0.07 & 0.45 \\
\hline
\end{tabular}


Table IA.7: Mean Delisting Returns with Tail Trimming of $\mathbf{5 \%}$

We report the monthly delisting returns (bias-corrected) based on matched portfolios of FoFs where the adjusted R-squared of the main regression model is at least $25 \%$ and the portfolio weight of the delisting fund is at least 5\%. We use 5\% tail trimming. Mean delisting returns and their standard deviations are in \% per month.

\begin{tabular}{lccccc} 
& $\begin{array}{c}\text { Number of } \\
\text { Matches }\end{array}$ & $\begin{array}{c}\text { Mean } \\
\text { Delisting } \\
\text { Return }\end{array}$ & $\begin{array}{c}\text { Bootstrapped } \\
\text { STD of Mean } \\
\text { Delisting } \\
\text { Return }\end{array}$ & $\begin{array}{c}\text { Non-parametric } \\
\text { p-value for } \\
\text { difference with } \\
\text { average HF return }\end{array}$ & $\begin{array}{c}\text { Absolute change } \\
\text { with respect to the } \\
\text { main results } \\
\text { expressed as a } \\
\text { number of standard } \\
\text { deviations of the } \\
\text { main results }\end{array}$ \\
\hline All & 1321 & -1.32 & 0.79 & 0.25 & 0.31 \\
\hline Liquidated & 338 & 0.90 & 1.31 & 0.17 & 1.02 \\
No Reason & 949 & -2.11 & 0.89 & 0.11 & 0.99 \\
\hline
\end{tabular}




\section{Table IA.8: Mean Delisting Returns Based on FoFs without Return Serial Correlation}

We report the monthly delisting returns (bias-corrected) based on matched portfolios of FoFs where the adjusted R-squared of the main regression model is at least $25 \%$ and the portfolio weight of the delisting fund is at least $5 \%$. We use $1 \%$ tail trimming. We use only those FoFs for which we cannot reject the hypotheses of no return serial correlation at the $1 \%$ significance level. Mean delisting returns and their standard deviations are in $\%$ per month.

\begin{tabular}{lccccc} 
& $\begin{array}{c}\text { Number of } \\
\text { Matches }\end{array}$ & $\begin{array}{c}\text { Mean } \\
\text { Delisting } \\
\text { Return }\end{array}$ & $\begin{array}{c}\text { Bootstrapped } \\
\text { STD of Mean } \\
\text { Delisting } \\
\text { Return }\end{array}$ & $\begin{array}{c}\text { Non-parametric } \\
\text { p-value for } \\
\text { difference with } \\
\text { average HF return }\end{array}$ & $\begin{array}{c}\text { Absolute change } \\
\text { with respect to the } \\
\text { main results } \\
\text { expressed as a } \\
\text { number of standard } \\
\text { deviations of the } \\
\text { main results }\end{array}$ \\
\hline All & 1362 & -1.34 & 0.96 & 0.19 & 0.28 \\
\hline Liquidated & 355 & 2.57 & 1.80 & 0.20 & 0.07 \\
No Reason & 974 & -2.82 & 1.11 & 0.06 & 0.33 \\
\hline
\end{tabular}




\section{Table IA.9: Mean Delisting Returns with 10 HFs in the FoFs' Portfolios}

We report the monthly delisting returns (bias-corrected) based on matched portfolios of FoFs where the adjusted R-squared of the main regression model is at least $25 \%$ and the portfolio weight of the delisting fund is at least $5 \%$. We use $1 \%$ tail trimming. We allow only $10 \mathrm{HFs}$ to be included into each FoF portfolio. The maximum portfolio weight is set to 0.15 . Mean delisting returns and their standard deviations are in $\%$ per month.

\begin{tabular}{lccccc} 
& $\begin{array}{c}\text { Number of } \\
\text { Matches }\end{array}$ & $\begin{array}{c}\text { Mean } \\
\text { Delisting } \\
\text { Return }\end{array}$ & $\begin{array}{c}\text { Bootstrapped } \\
\text { STD of Mean } \\
\text { Delisting } \\
\text { Return }\end{array}$ & $\begin{array}{c}\text { Non-parametric } \\
\text { p-value for } \\
\text { difference with } \\
\text { average HF return }\end{array}$ & $\begin{array}{c}\text { Absolute change } \\
\text { with respect to the } \\
\text { main results } \\
\text { expressed as a } \\
\text { number of standard } \\
\text { deviations of the } \\
\text { main results }\end{array}$ \\
\hline All & 1284 & -0.20 & 0.84 & 0.17 & 1.50 \\
\hline Liquidated & 337 & 1.35 & 1.47 & 0.24 & 0.76 \\
No Reason & 922 & -0.53 & 1.00 & 0.08 & 2.44 \\
\hline
\end{tabular}


Table IA.10: Mean Delisting Returns with up to 26 HFs in the FoFs' Portfolios

We report the monthly delisting returns (bias-corrected) based on matched portfolios of FoFs where the adjusted R-squared of the main regression model is at least $25 \%$ and the portfolio weight of the delisting fund is at least $5 \%$. We use $1 \%$ tail trimming. We allow up to $26 \mathrm{HFs}$ to be included into each FoF portfolio. The algorithm proceeded in much the same way as our basic procedure but stopped adding funds to the portfolio when any fund would have an estimated weight of less than 0.02 . Using this procedure, the average number of hedge funds in a matching portfolio was 12.51. Mean delisting returns and their standard deviations are in $\%$ per month.

$$
\begin{array}{ccc}
\begin{array}{c}
\text { Number of } \\
\text { Matches }
\end{array} & \begin{array}{c}
\text { Mean } \\
\text { Delisting } \\
\text { Return }
\end{array} & \begin{array}{c}
\text { Bootstrapped } \\
\text { STD of Mean } \\
\text { Delisting }
\end{array}
\end{array}
$$

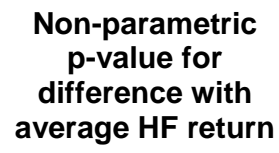

Absolute change with respect to the main results expressed as a number of standard deviations of the main results

\begin{tabular}{lccccc}
\hline All & 1316 & -1.28 & 0.91 & 0.19 & 0.34 \\
\hline Liquidated & 325 & 2.80 & 1.70 & 0.21 & 0.06 \\
No Reason & 960 & -2.65 & 1.04 & 0.07 & 0.50 \\
\hline
\end{tabular}


Table IA.11: Mean Delisting Returns with a Partial Unwind of Positions in the Exiting HF We report the monthly delisting returns (bias-corrected) based on matched portfolios of FoFs where the adjusted R-squared of the main regression model is at least $25 \%$ and the portfolio weight of the delisting fund is at least 5\%. We use $1 \%$ tail trimming. Mean delisting returns and their standard deviations are in \% per month. We assume the FoF was able to identify the exiting hedge fund and to unwind half its position prior to the exit. That half of the estimated weight is equally distributed among the surviving hedge funds in that FoF portfolio.

\begin{tabular}{lccccc} 
& $\begin{array}{c}\text { Number of } \\
\text { Matches }\end{array}$ & $\begin{array}{c}\text { Mean } \\
\text { Delisting } \\
\text { Return }\end{array}$ & $\begin{array}{c}\text { Bootstrapped } \\
\text { STD of Mean } \\
\text { Delisting } \\
\text { Return }\end{array}$ & $\begin{array}{c}\text { Non-parametric } \\
\text { p-value for } \\
\text { difference with } \\
\text { average HF return }\end{array}$ & $\begin{array}{c}\text { Absolute change } \\
\text { with respect to the } \\
\text { main results } \\
\text { expressed as a } \\
\text { number of standard } \\
\text { deviations of the } \\
\text { main results }\end{array}$ \\
\hline All & 1392 & -3.73 & 1.88 & 0.39 & 2.26 \\
\hline Liquidated & 358 & 4.46 & 3.51 & 0.12 & 1.01 \\
No Reason & 998 & -6.76 & 2.18 & 0.19 & 3.29 \\
\hline
\end{tabular}

